\title{
Evaluation of Meshra's Technique in Unilateral Cleft Lip Deformity
}

\author{
Tawfeeq Waleed Tawfeeq ${ }^{1}$, Afraa Qasim Al-Zerkani², Thaer Kareem Alwan ${ }^{3}$ \\ ${ }^{1}$ F.I.B.M.S (Fellow of Iraqi Board Member of Specialization) [Plastics], Consultant Plastic Surgeon, Medical City \\ Institute, Baghdad-Iraq, ${ }^{2}$ M.B.Ch.B. (Medicine Bachelor Churchery Bachelor), Diploma of Anesthesia, Director of \\ Pediatric anesthesia Dept., Children Welfare Teaching Hospital, Medical City Institute, Baghdad-Iraq, \\ ${ }^{3}$ M.B.Ch.B., C.A.B.P (Certificate of Arab Board of Plastics), Medical City Institute, Burn Unit Center, Baghdad- \\ Iraq
}

\begin{abstract}
Background: White roll vermillion turn down flap is a modification on Millard's technique of rotation advancement repair for unilateral primary cleft lip deformity.

Aim of Study: This research to evaluate a new modification on Millard's technique of primary unilateral chieloplasty.

Patients and Methods: A prospective study was done and involved 20 patients were surgically treated by Meshra's technique of white roll vermillion turn down flap at Al-Shaheed Ghazii Alharriri and Al-Wasty hospital between April 2015 to April 2017. 12 male versus 8 female presented to us with unilateral cleft lip there ages were ranging between 3 months to 30 months, these patients surgically treated by white roll vermillion turn down flap.
\end{abstract}

Results: A prospective study was involved of 20 cases of primary cleft lip repair with this technique, we have achieved 17 cases with a good symmetry and peaking of cupids bow with no vermillion notching of the lips and without major complications.

Conclusion: White roll vermillion turn down flap gave us a good look of the cleft patient and satisfactory for his family. It's applicable and takes same time for Millard's technique.

Key words: White roll, Millard's methods, vermillion, cleft lip, cupid bow, Philletrum.

\section{Introduction}

First surgical closure of cleft lip was done in china in 390 A.D. after that many methods had being introduced

\section{Corresponding Author:}

\section{Ali Laibi Zamil}

M.B.Ch.B., MRCS (Ireland),

Instructor, Surgical Department, College of Medicine,

Ibn Sina University of Medical and Pharmaceutical

Sciences, Iraq-Baghdad.

E-mail: ali_zamil@hotmail.com

Mobile: $+968-7714322658$ including straight line closure, lateral advancement, and Z-plasties. The idea of lateral flap advancing into the upper lip in combination with medial segment down rotation was introduced by Ralph Millard in early 1950s. Millard technique of rotational advancement flap, gained wide world acceptance and the Majority of cleft lip repair is done by using this method

Millard technique had advantage of being simple and flexible operation and can be described as cut-as you-go. The resultant scar of Millard's operation usually will place at the site of new philltral column which give lip satisfactory aesthetic appearance. However there 
are many deficiencies in Millard operation like limited medial component rotation, vermilion deficiency and question about its application for wide cleft lip for assessing of problem that associated with Millard's operation, many modifications had been postulated like Mohler, Noordhoof and Oricuka modification ${ }^{[4,5]}$.

In this study we evaluated white roll vermilion turn down flap (Meshras techniques) as one modification of Millard technique for primary unilateral cleft lip repair.

\section{Patient and Method}

Between April 2015 April 2017, 20 patients (12 male versus 8 female) were presented to us with unilateral cleft lip. Their ages were ranging between 3-30 months; those patients were surgically treated using white roll vermilion turn down flap technique as one of Millard's technique modification. None of our patients had preoperative orthodontic appliance or lip adhesion. All patients were subjected to routine preoperative investigation with informed consent obtained from the patients. Patients are shown in (table 1) below.

Table 1: Show Patients' data and pathology.

\begin{tabular}{|c|c|c|c|c|c|}
\hline Pt. & Gender & Age & Cleft site & Cleft type & $\begin{array}{c}\text { Associated cleft } \\
\text { alveolus and palate }\end{array}$ \\
\hline 1. & $\hat{0}$ & 3,5 month & Rt. & incomplete & -ve \\
\hline 2. & $\widehat{0}$ & 3 month & Rt. & incomplete & -ve \\
\hline 3. & q & 3 month & Lt. & incomplete & -ve \\
\hline 4. & $\widehat{0}$ & 3,5 month & Rt. & complete & $+\mathrm{ve}$ \\
\hline 5. & q & 4 month & Lt. & incomplete & -ve \\
\hline 6. & $\hat{0}$ & 3,5 month & Lt. & complete & $+\mathrm{ve}$ \\
\hline 7. & 우 & 6 month & Rt. & incomplete & -ve \\
\hline 8. & q & 5,5 month & Rt. & incomplete & -ve \\
\hline 9. & $\hat{0}$ & 5 month & Rt. & complete & $+\mathrm{ve}$ \\
\hline 10. & $\hat{0}$ & 3 month & Rt. & complete & $+\mathrm{ve}$ \\
\hline 11. & q & 4 month & Rt. & complete & $+\mathrm{ve}$ \\
\hline 12. & $\hat{0}$ & 5,5 month & Rt. & incomplete & -ve \\
\hline 13. & 우 & 3 month & Lt. & incomplete & -ve \\
\hline 14. & $0^{\pi}$ & 4,5 month & Rt. & incomplete & -ve \\
\hline 15. & 우 & 3,5 month & Rt. & complete & $+\mathrm{ve}$ \\
\hline 16. & $\hat{0}$ & 6 month & Rt. & incomplete & -ve \\
\hline 17. & $\sigma^{\lambda}$ & 5,5 month & Rt. & incomplete & -ve \\
\hline 18. & $0^{\lambda}$ & 4.5 month & Rt. & incomplete & -ve \\
\hline 19. & q & 2,5 year & Lt. & complete & $+\mathrm{ve}$ \\
\hline 20. & 0 & 3 month & Lt. & complete & $+\mathrm{ve}$ \\
\hline
\end{tabular}




\section{Operative Technique and Marking:}

All operations were undertaken under general anesthesia. Preoperative marking began as usual Millard technique markings. Point 1 will represented the lower point of cupid's bow and then the peak of cupid's bow on non-clefted site will mark as point 2 . The distance between point 1 and 2 is measured and the proposed site of peak of cupid's bow on cleft side is marked as point 3 which should be equal to the distance between point 1 and 2, usually $2.5 \mathrm{~mm}$. the lateral lip segment is then marked, where point $1^{-}$is located when the white roll begins to dissipate over the lip curvature. The rotational flap is marked on medal lip segment as gentle convexity following cleft margin to the columellar base, where it extending transversely, ending in back-cut before crossing, where the normal philtral column. A small peanut-shaped (c-flap) which is columllar based flap is created which can be used either to reconstructed the

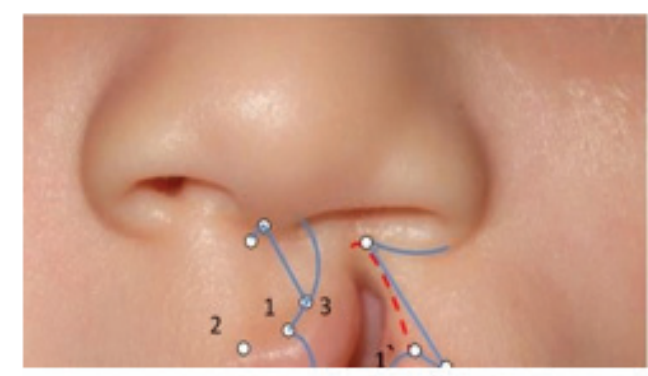

Figure (2) lateral side marking

\section{Operative Method:}

After finishing of our marking, local infiltration of $1 \%$ xylocaine with $1: 100,000$ is given, and after waiting 7-10 minutes the operation is begin. The incision along usual Millard rotation-advancement flap is done. Then an incision is done on the medial segment of lip extending from point 3 to point 1 (just above the white roll). At point 1 , a vertical incision is made along the vermilion reach to opposite site of point 1 on free margin of mucosa. Then medial vermilion and part of orbicularis muscle nostril or lengthen the columella.

The vertical incision of lateral segment is marked extending from point $1^{-}$toward the nasal site and curved gently along normal side nasal ala. In those cases with wide-cleft lip, both L and M flap is marked. M-Flap is create for nasal floor closure, and L-flap is use to fill piriform aperture defect. After that white roll vermillion turn down flap is marked first on the medial segment of the lip by drawing line extended from point 3 just above while roll ending in point 1 ( $2.5 \mathrm{~mm}$ length), then from point 1 a vertical line is drawn perpendicular along the vermilion to be end on the opposite site of free margin of the mucosa. On the lateral segment, line is extended from point $1^{\prime}$ - to point $3^{\prime}$ laterally just above the white roll (distance between $1^{-}-3^{-}$should equal 1-3). Then vertical line is drawn perpendicular on the vermilion extending from $1^{-}$to the opposite site of free margin of the mucosa.

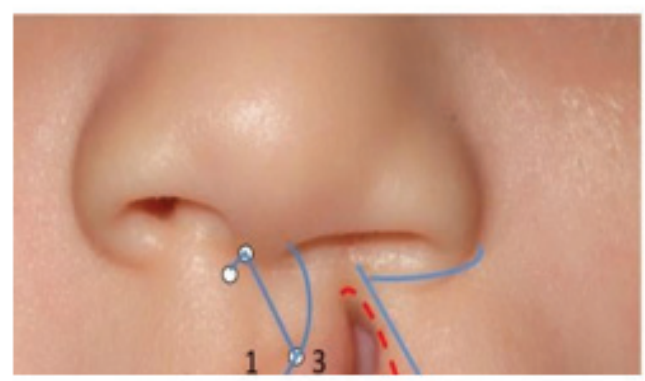

Figure (1) medial side marking

within our incision is discarded. By using blunt scissor, the orbicularis muscle on the medical lip segment is carefully dissected from its overlying skin and underling mucosa (not more than the mid-distance of Cupid's bow). Then we proceed to lateral lip segment an incision is done extended from point $1^{-}$to point $3^{-}$also just above white roll, the perpendicular incision is extended from point $1^{-}$along the vermilion to the opposite point to $1^{-}$in free surface of mucosa of the vermilion. 
A small triangle of tissue (included both muscle and skin) is excised between vermilion and Millard incision. Then white roll vermilion flap is railed with orbicularis oris muscle within it. When thickness of lateral vermilion is excised, if its length is more, it trimmed to appropriate dimension. After finishing of these steps, when we needed, $\mathrm{L}$ and $\mathrm{M}$ flaps are in setting in this position. The orbicularis muscle suture by $4 / 0$ polyglactine suture under both point 3 and point $3^{-}$then skin closure of white roll vermilion flap is done by suture point 3 to point $3^{-}$and point 1 to point $1^{-}$using $5 / 0$ polygloctive simple interrupted suture. The final suture line lies above white roll ( $1 \mathrm{~mm}$ above it), philtral column and in midline along the vermilion figure (3) (4) (5) (6).

Simple dressing then apply to the word, patients were discharge in next day keeping them on oval antibiotic for at least 5 day after operation. First postoperative visit will schedule at $7^{\text {th }}$. day postoperatively. All patients were kept regular follow up at least 3 months postoperatively.

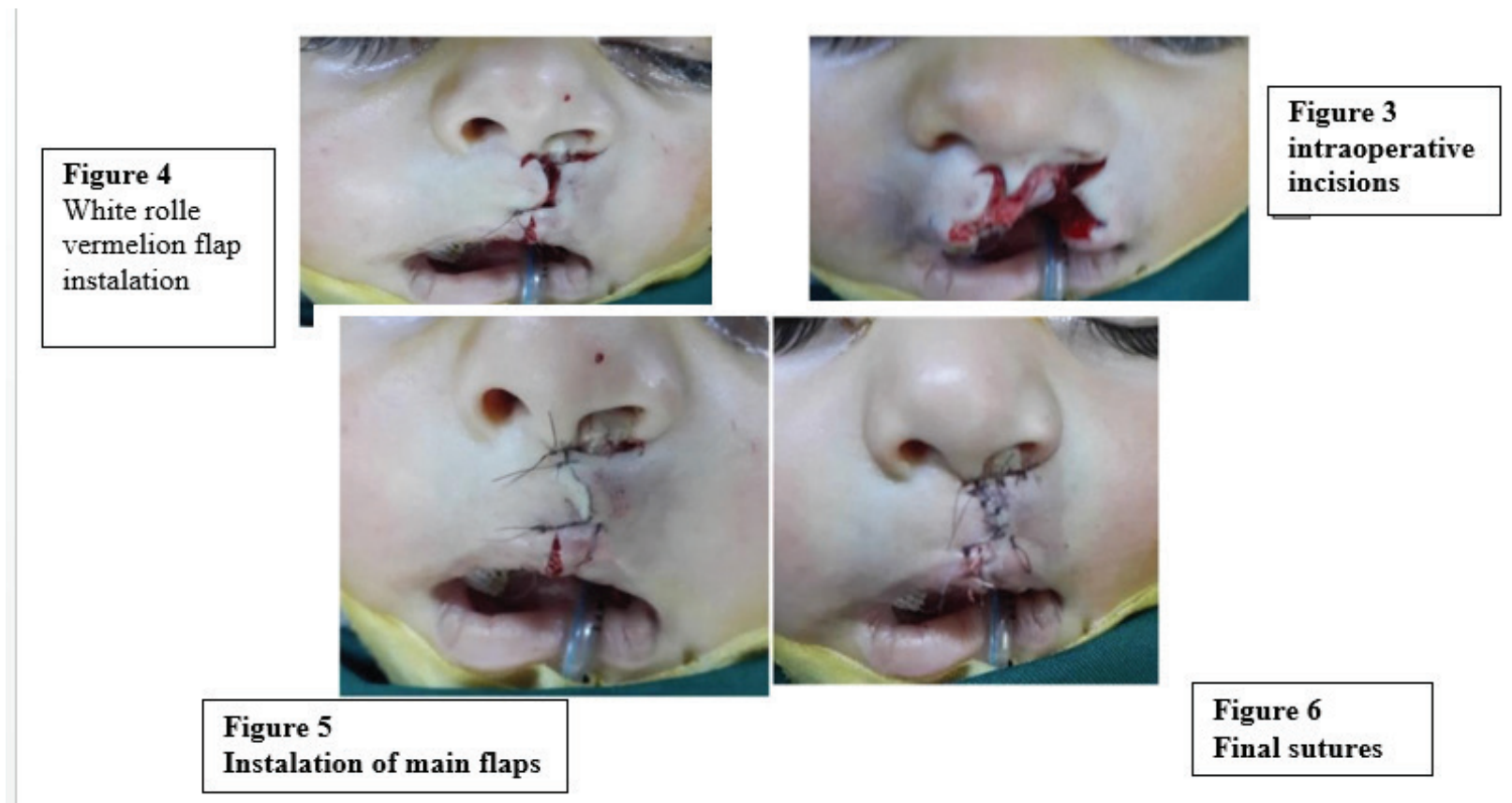

\section{Results}

Twenty patients with unilateral cleft lip were subjected to modified Millard rotation advancement flap by using white roll vermillion turn down flap. Our result were subjectively evaluated postoperatively depending on assessment of different parameters like white roll alignment, cupid's bow symmetry, vermilion match, evenness of the vermilion, tubercle fullness and scar appearance. Also patients parent satisfaction we taking in consideration in evaluation of our postoperative results. According to base mentioned criteria, 17 out of 20 patients had satisfactory postoperative result with symmetrical cupid bow, smooth well aligned white roll and vermilion with even thickness without any notching without any notching during follow up period. The results scar was barely visible after 6 months without causing notching of cupid bow, with no hypertrophic scar was seen fig. (7)(8)(9). 3 out of 20 patients had poor results with one patient had badly aligned white roll, and 2 patients had vermilion notching. No major postoperative complications were seen in our entire patients; only one of our patients had mild skin infection and in 2 patients had wound dehiscence at midline vermilion suture. All of those complications had no later squally on result; a part from one patient who had wound dehiscence at vermilion from one patient who had wound dehiscence at vermilion was later on developed vermilion notching. 


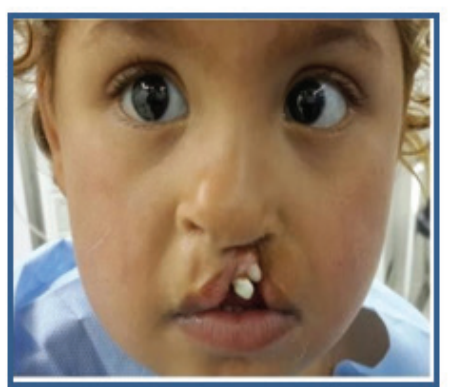

Figure (7) preoperative

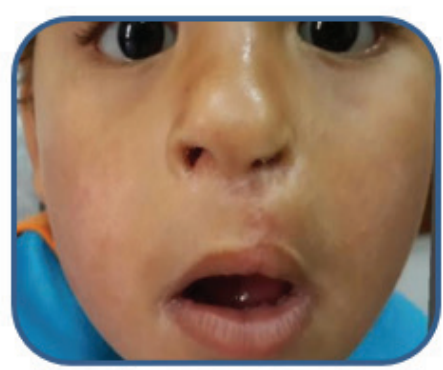

Figure (8) 3months postoperative

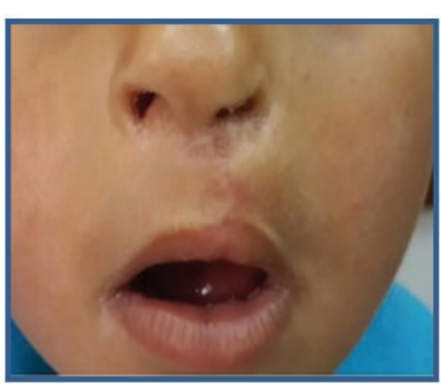

Figure (9) closed view

\section{Discussion}

One of the rewarding and challenging tasks in the plastic surgery is cleft lip repair since cleft had both physical and psychological impact on the patient. In 1955, a new era in cleft lip surgery had evolved when Dr. Millard presented his novel method of rotational advancement flap technique for cleft lip repair in first international congress of plastic surgery in Stockholm. Up to $84 \%$ of the surgeon used Millard operation for cleft lip repair. Many modifications had being postulated for Millard operation; these modifications could be useful or had detrimental effect

In this study 20 patients presented to us with unilateral cleft lip were surgically treated using white roll vermilion turn down flap as modification of Millard's rotational advancement flap. Our results were subjectively evaluated and 17 out of 20 patients had postoperative symmetrical Cupid's bow, well and smooth aligned white roll, vermilion with even thickness without notching, and the scar was barely visible after 6 month of follow up without causing of stretching of Cupid's bow. White roll vermilion flap as modification of Millard-technique was introduced by PK. Misha were he used it in (100) cases with satisfactory results with symmetrical and protrusive vermilion together with smooth curve cupid's bow with regular outlive of white roll that can trace by gazing age from lateral to medial portion of lip ${ }^{[8]}$.
The basic principle concept of using white roll vermilion turn down flap was based originally on the using of the lateral segment for central part reconstruction in cases of bilateral cleft lip, where the muscle of lateral lip segment rotated down with full thickness vermilion to reconstruct central vermilion ending with single vertical scar in red lip under the depth of cupid bow. By using of white roll vermilion turn down flap this will lead to place the final scar of closure in Millard technique.

Present of midline cupid bow scar will mimic the embryonic fusion line that occur during embryological development of the upper lip, where the vermilion, which is develop from the maxillary process, fused in midline represented by frenulum ${ }^{[9]}$ The advantage scar in traditional Millard operation. One of the disadvantages of Paramedian scar is that it continuous with final skin closure of traditional Millard technique, this may lead to upward rotation and notching of the vermilion, which is especially noticed in short vertical length of cleft side. One of other setback of traditional Millard's technique is vermilion notching which especially occur due it straight line closure of mention. In order to correct this problem, z-plasty was introduced to solve this problem. In our method, no z-plasty was used as parmedian scar is shifted to median scar which not continuous with final wound closure, thus not causing notching of vermilion when it contracted later on. Another cause of vermilion notch in original Millard's technique is that the vermilion in medial segment of lip (non-cleft site) was often deficient when compared to lateral segment of lip 
(cleft sit) ${ }^{[2]} \cdot$ Millard described lateral vermilion based flap to augment medial vermilion which was fashioned as tongue of posterior mucosa that brought to medial side by relaxing incision. Later on described another modification by using tongue in grove ${ }^{[1]}$. Both of these modifications cannot prevented vermilion notch, since the deficient tissue is already presented because laterally based triangular vermilion flap contained no adequate tissue (just contused mucosa which not sufficient to augment medial segment) ${ }^{[10]}$. In this method by using white roll vermilion turn down flap which contained adequate tissue of vermilion, white roll, and underlying orbicularis oris muscle, all of these tissues is sufficient to augment medial segment of lip ending in full vermilion with even appearance. In this method any excess tissue is discarded from thick site so that we achieved symmetrical even shaped tubercle.

Cutting used lateral triangular flap which described by Noordhoff ${ }^{[1]}$ to overcome of the problem of lateral and medial segment thickness discrepancy when repairing of unilateral cleft lip. However, there are many problems associated with using of Noordhoff technique including:

1- Cannot bring adequate tissue to augment the deficient medial cleft vermilion.

2- The ideal and parallel relationship between both white roll and redline was not adequately maintained which lead to cupid bow symmetry discrepancy.

3- Noord hoof's triangular flap can produce unsightly trapdoor deformity which should be deal with it later on ${ }^{[16,11]}$.

4 Finally in this method, the pars marginalis port of the orbicularis oris muscle was adequately and precisely bring together, which provided solution of another component of vermilion notching which is improper muscle repair at vermilion border.

5- One of the most noticeable drawback of using white vermilion turn down flap is that it needed highly précised incision above the white roll with précised
Medico-legal Update, October-December 2021, Vol.21, No. 4361 suturing, if the incision was not done in precisely method, this may violated white roll appearance or may even lead to absent of white roll in reconstructed lip.

\section{Conclusion and Recommendation}

Vermilion reconstruction in primary unilateral cleft lip repair by using white roll vermilion turn down flap is one of modification of Millard technique that can be applicable for treatment of unilateral cleft lip with satisfactory aesthetic result, it easily to be learned and nearly have same time of operation as Millard technique.

Conflict of Interest: The authors declare that they have no conflict of interest.

\section{Source of Funding: Self.}

Ethical Clearance: Taken

\section{References}

1- Samnel Stal et .al fifty years of Millard rotation advancement look back and moving forward. Plastic and reconstructive surgery, 2008; 123(4):13641377.

2- Sdi Noshwwn Jan et .al. Reducing the vermilion notch in primary lip repair:- 2-plasty versus the Noord triangular flap. Plastic and reconstructive surgery . 2010; 2295):307-310.

3- Ross D. Furhadieh, Nwil W. Bulatrode, Sabrina Cuguo. Plastic and reconstructive surgery. Appronches and techniques, $1^{\text {st }}$.ed, Wiley, oxford, u.k, 2015; pp.209.

4- Drik D. Lazarus et.al. Repair of unilateral cleft lip. A comparison of the five technique. Annals of plastic surgery. 1998; 41(6):587-594.

5- Thomas J. Stizman, John A. Givotto, Jeffery K. Marcus. Current surgical practice in cleft care: unilateral cleft lip repair. Plastic and reconstructive surgery. 2008; 121(5):261e-270e.

6- Jonthan M. Skyes, Trains T. Toll Efeson. Management of cleft lip deformity. Facial plastic surgery Cl.n, 2005; 13:157-167.

7- John B. Mulliken, Dolores Martinez- perez. The principle of rotation advancement for repair of unilateral complete cleft lip and nasal deformity: technical variation and analysis of results. Plastic and reconstructive surgery, 1999;104(5):1247- 
362 Medico-legal Update, October-December 2021, Vol.21, No. 4 1260.

8- Rk.Mishra, Amit Agarwai white roll vermilion turn down flap in prmovy unilatearal cleft lip repair: a novel approach. Indian jounal of plastic surgery, 2015; 48(2):178-184.

9- Gosla Sririvas Reddy et.al. Choice of incision for primary unilateral complete cleft lip: a comparative study of outcome in 796 patients and reconstructive surgery, 2008; 1213): 932-940.

10- Reymond Tse. Unilateral cleft lip: principle and practice of surgical management. Seminar in plastic surg. 2012; 26:145-155.

11- Power Rs, Ptail Sm., Kleiman Me. A geometrically sound technique of vermilion repair in unilateral cleft lip. Br. J. plastic surg., 2007; 60: 422-5 